\title{
Candida albicans/Staphylococcus aureus Dual-Species Biofilm as a Target for the Combination of Essential Oils and Fluconazole or Mupirocin
}

\author{
Aleksandra Budzyńska · Sylwia Różalska • Beata Sadowska • Barbara Różalska $(\mathbb{D}$
}

Received: 28 April 2017 / Accepted: 8 August 2017/Published online: 19 August 2017

(C) The Author(s) 2017. This article is an open access publication

\begin{abstract}
The effectiveness of essential oils (EOs), fluconazole (FLU) and mupirocin (MUP) used alone or in combination against mono-species and mixed Candida albicans/Staphylococcus aureus biofilms was examined. An experimentally established dualspecies biofilm model, verified by fluorescence microscopy and viable cell counting, was used. Selected commercial EOs were tested: geranium, citronella and clove oils, which have been chemically characterized and found to differ in the content of the main components (qualitative and quantitative). As expected, $C$. albicans and S. aureus biofilms were less susceptible to fluconazole and mupirocin action, respectively, compared to the planktonic counterparts. However, the drug effectiveness in combination with the EOs was significantly improved, giving
\end{abstract}

A. Budzyńska

Laboratory of Microbiological and Technical Services,

University of Lodz, Banacha 12/16, 90-237 Lodz, Poland

S. Różalska

Department of Industrial Microbiology and

Biotechnology, University of Lodz, Banacha 12/16,

90-237 Lodz, Poland

B. Sadowska · B. Różalska ( $₫)$

Department of Immunology and Infectious Biology,

Faculty of Biology and Environmental Protection,

Institute of Microbiology, Biotechnology and

Immunology, University of Lodz, Banacha 12/16,

90-237 Lodz, Poland

e-mail: barbara.rozalska@biol.uni.lodz.pl enhancement of biofilm eradication than caused by the antibiotics alone. Moreover, dual-species biofilm formation was limited by sub-MIC of EOs, and preformed mixed biofilm was eliminated more efficiently by combined action of drugs and EOs.

Keywords Dual-species bacterial/fungal biofilm . Essential oils

\section{Introduction}

Candida albicans in specific host-dependent conditions is an effective opportunistic organism. Invasive candidiasis usually results from yeast-to-hyphae transformation and tissue colonization due to the formation of a biofilm [1]. The possibility of the development of polymicrobial biofilms, consisting of both fungi and bacteria, should also be considered in pathogenesis of various infections. C. albicans is able to grow together with Staphylococcus aureus, S. epidermidis and Enterococcus sp. in the course of blood-borne infections, with Gardnerella vaginalis during vaginal infections, Pseudomonas aeruginosa in cystic fibrosis and diverse other bacteria or fungi in oral as well as in skin/wound infections [2-6].

Since it is known that $C$. albicans isolates resistant to azoles emerge often, several approaches to overcome this have been proposed. The most convincing is using a combination of fluconazole and various classes of non-antifungal agents [8, 9]. Similarly, successful 
treatment of drug-resistant $S$. aureus is a major challenge for medicine. The reports on the increasing resistance to pseudomonic acid (mupirocin)—one of the most potent topical antibiotics used against MSSA and MRSA - are of serious concern and also necessitate the search for alternatives [10].

Interesting strategies of the treatment are derived from the experience of ethnomedicine inspired by the use of natural-origin products. Our laboratory has investigated antimicrobial activity of plant essential oils, which became the basis for the present study [11].

\section{Materials and Methods}

\section{Research Material}

- Suspensions of C. albicans ATCC 10231 cultured in RPMI-1640 medium with $2 \%$ glucose and $S$. aureus NCTC 8325-4 in TSB with $0.25 \%$ glucose.

- Geranium, citronella and clove oils (EOs) from Pollena Aroma, Poland; fluconazole (FLU) and mupirocin (MUP) from Sigma, USA.

\section{Minimal Inhibitory Concentration (MIC)}

The MICs of the EOs tested at a concentration range of $0.48-7.8 \mu \mathrm{ml}^{-1}$ were determined by a broth microdilution method according to the EUCAST guidelines [12] with minor modifications [11]. The same method was used to assess MICs of drugs: The concentration range was fluconazole $-0.25-8.0 \mu \mathrm{g} \mathrm{ml}^{-1}$ and mupirocin- $0.0625-8.0 \mu \mathrm{g} \mathrm{ml}^{-1}$.

\section{Minimal Biofilm Eradication Concentrations (MBEC)}

The MBEC of EOs, FLU, MUP used separately or in combination were determined against $C$. albicans and $S$. aureus 24-h-old biofilms formed in the 96-well microplates. Biofilms were treated for the next $24 \mathrm{~h}$ with EOs (range MIC-16 $\times$ MIC). In other set of experiments, the $C$. albicans biofilm was exposed to fluconazole (range MIC-512 $\times$ MIC), while the $S$. aureus biofilm was exposed to mupirocin (range MIC_-16 × MIC). The MBEC, decreasing metabolic activity of biomass by 50 and $80 \% \quad\left(\mathrm{MBEC}_{50}\right.$; $\mathrm{MBEC}_{80}$ ), were evaluated using XTT reduction assay, as recommended by the manufacturer. The combined effect of FLU or MUP with EOs was assessed in a separate experiment, by applying each agent at a predetermined $\mathrm{MBEC}_{50}$.

\section{Dual-Species Biofilm Eradication}

- Evaluation of fungi and bacteria participation in mixed biofilm, developed on the surface of round glass slides (area of $19.6 \mathrm{~mm}^{2}$ ) placed in the wells of 96-well microtiter plates, was performed. Three variants of suspension $(100 \mu \mathrm{l})$ application $\left(1 \times 10^{6} \mathrm{CFU} / \mathrm{ml}\right.$ of yeast or $1 \times 10^{7} \mathrm{CFU} / \mathrm{ml}$ of bacteria) were performed: (A) yeast $2 \mathrm{~h}$ before bacteria; (B) bacteria $2 \mathrm{~h}$ before yeast; and (C) yeast and bacteria simultaneously. A quantitative evaluation was performed after 24 -h incubation at $37{ }^{\circ} \mathrm{C}$. Slides were removed, washed in PBS, transferred to the tubes with $1 \mathrm{ml}$ of PBS and sonicated $(5 \mathrm{~min})$. Tenfold dilutions were made and cultured on SDA medium supplemented with chloramphenicol (selective for Candida) and Chapman medium (selective for Staphylococcus). After overnight incubation at $37^{\circ} \mathrm{C}$, the colonies were counted.

- Morphology of mixed biofilms developed in a Lab-Tek II chamber slide (Nunc, Denmark) was tested after staining with fluorescent dyes: $5 \mu \mathrm{M}$ of SYTO 9 (Molecular Probes, USA) and $0.5 \mathrm{ml}$ of calcofluor white (Sigma, USA). The images were captured using AxioCam HRC camera combined with an Axiovert $200 \mathrm{M}$ (Zeiss, Germany) inverted microscope equipped with a Plan-Neofluar objective $(63 \times / 1.25$ oil $)$.

- Dual-species preformed biofilm (24 h old) was treated with FLU, MUP applied alone or in combination with $\mathrm{EO}$, each at $\mathrm{MBEC}_{50}$ active against mono-species biofilms. The degree of biofilm eradication was evaluated after 24-h incubation at $37{ }^{\circ} \mathrm{C}$, using Alamar Blue reduction assay according to the manufacturer's recommendations.

\section{Statistical Analysis}

The results are provided as the mean \pm S.D. When applicable, statistical differences between groups were evaluated using the Mann-Whitney $U$ test using STATISTICA 12.0 software (StatSoft Inc., USA). $P<0.05$ was considered significant. 


\section{Results}

Commercial EOs-geranium, citronella and clove oils, differing in content of the main componentswere chosen based on the results of Budzyńska et al. [11]. Eugenol was identified in the clove oil (86.2\%) but not in citronella and geranium oils. Clove oil contained also $10.4 \%$ of (E)- $\beta$-caryophyllene, which was detected in the two other oils at trace levels (0.2-0.9\%). Citronella and geranium oils enclosed compounds absent in clove oil-high concentration of citronellal (36.2\%) and geraniol (22.4\%) in citronella oil-whereas geranium oil was rich in geraniol $(10.5 \%)$ and chemically similar citronellol (44.0\%). Geranium oil as the only contained also citronellyl formate $(9.8 \%)$.

The first step was an evaluation of mono-species biofilm of $C$. albicans and $S$. aureus susceptibility to eradication by conventional drugs alone or in combination with the oils. The results presented in Table 1 indicate that the $\mathrm{MBEC}_{50}$ of EOs for $C$. albicans biomass was obtained at $2 \times \mathrm{MIC}$ and the $\mathrm{MBEC}_{80}$ value was reached at $4 \times$ MIC. The higher concentrations of EOs were necessary to reduce $S$. aureus biofilm. When EOs were tested together with the drugs used at $\mathrm{MBEC}_{50}$ established when used separately, significantly stronger reduction in biomass was observed (Fig. 1).

Next, the effectiveness of mixed biomass destruction by combining EOs and drugs was tested. It required the establishment of optimum conditions for the dual-species biofilm model. The data were obtained by differential fluorescent staining, morphological analysis and CFU calculation. The microscopy observations indicated that the simultaneous occurrence of the contact of microbes with the surface (variant C) resulted in the formation of equally numerous dual-species populations (Fig. 2c), with the presence of different yeast morphotypes (blastospores, germ tubes, pseudohyphae and hyphae) within. Many of the staphylococcal clusters were seen to be adhered mainly to hyphae. In variant B, the formed biofilm consisted mainly of $S$. aureus microcolonies (Fig. 2b). However, when the adhesion of C. albicans started $2 \mathrm{~h}$ before $S$. aureus (variant A), fungal cell density was almost equal to $S$. aureus microcolonies, and a relatively low variability of $C$. albicans morphological forms was found (Fig. 2a). The CFU counts revealed that only simultaneous application of $C$. albicans and $S$. aureus on the surface resulted in the formation of a greater number of $C$. albicans (1.7 times higher than observed in the corresponding mono-species biofilm). In contrast, when the application of $S$. aureus preceded C. albicans, the biofilm consisted mainly of $S$. aureus microcolonies with the number of yeasts being 22 times lower than found in the mono-species biofilm. In all variants $(\mathrm{A}-\mathrm{C})$, the number of $S$. aureus in the mixed biofilms was up to 7.9 times higher than in the control mono-species staphylococcal biofilm.

Version $\mathrm{C}$ of the mixed biofilm formation model was selected for the next stage of the study. It was demonstrated that FLU or MUP in combination with clove oil (selected as the most active) against preformed mixed biofilm was very efficient. It resulted in a tenfold increase in anti-biofilm activity of fluconazole and a fourfold increase in the total
Table 1 Essential oils (EOs) and chemotherapeutics (FLU, MUP) anti-biofilm activity

The minimal concentration able to eradicate $50 \%$ $\left(\mathrm{MBEC}_{50}\right)$ or $80 \%$ $\left(\mathrm{MBEC}_{80}\right)$ of preformed mono-species biofilm metabolic activity, evaluated by XTT reduction assay

\begin{tabular}{|c|c|c|c|c|}
\hline \multirow[t]{2}{*}{ Oils } & \multicolumn{2}{|c|}{ C. albicans ATCC 10231} & \multicolumn{2}{|c|}{ S. aureus NCTC 8325-4 } \\
\hline & $\mathrm{MBEC}_{50}$ & $\mathrm{MBEC}_{80}$ & $\mathrm{MBEC}_{50}$ & $\mathrm{MBEC}_{80}$ \\
\hline Geranium & 1.9 & 3.8 & 7.6 & 15.6 \\
\hline$\left(\mu \mathrm{l} \mathrm{ml} l^{-1}\right)$ & $(2 \times \mathrm{MIC})$ & $(4 \times \mathrm{MIC})$ & $(4 \times \mathrm{MIC})$ & $(8 \times \mathrm{MIC})$ \\
\hline Citronella & 1.9 & 3.8 & 3.8 & 15.6 \\
\hline$\left(\mu \mathrm{l} \mathrm{ml} l^{-1}\right)$ & $(2 \times \mathrm{MIC})$ & $(4 \times \mathrm{MIC})$ & $(4 \times \mathrm{MIC})$ & $(16 \times \mathrm{MIC})$ \\
\hline Clove & 1.9 & 3.8 & 15.6 & 31.2 \\
\hline$\left(\mu 1 \mathrm{ml}^{-1}\right)$ & $(2 \times \mathrm{MIC})$ & $(4 \times \mathrm{MIC})$ & $(4 \times \mathrm{MIC})$ & $(8 \times \mathrm{MIC})$ \\
\hline $\begin{array}{l}\text { Fluconazole } \\
\left(\mu \mathrm{g} \mathrm{ml}^{-1}\right)\end{array}$ & $\begin{array}{l}64.0 \\
(64 \times \mathrm{MIC})\end{array}$ & $\begin{array}{l}>512.0 \\
(>512 \times \mathrm{MIC})\end{array}$ & - & - \\
\hline $\begin{array}{l}\text { Mupirocin } \\
\left(\mu \mathrm{gml}^{-1}\right)\end{array}$ & - & - & $\begin{array}{l}1.0 \\
(2 \times \mathrm{MIC})\end{array}$ & $\begin{array}{l}4.0 \\
(8 \times \mathrm{MIC})\end{array}$ \\
\hline
\end{tabular}



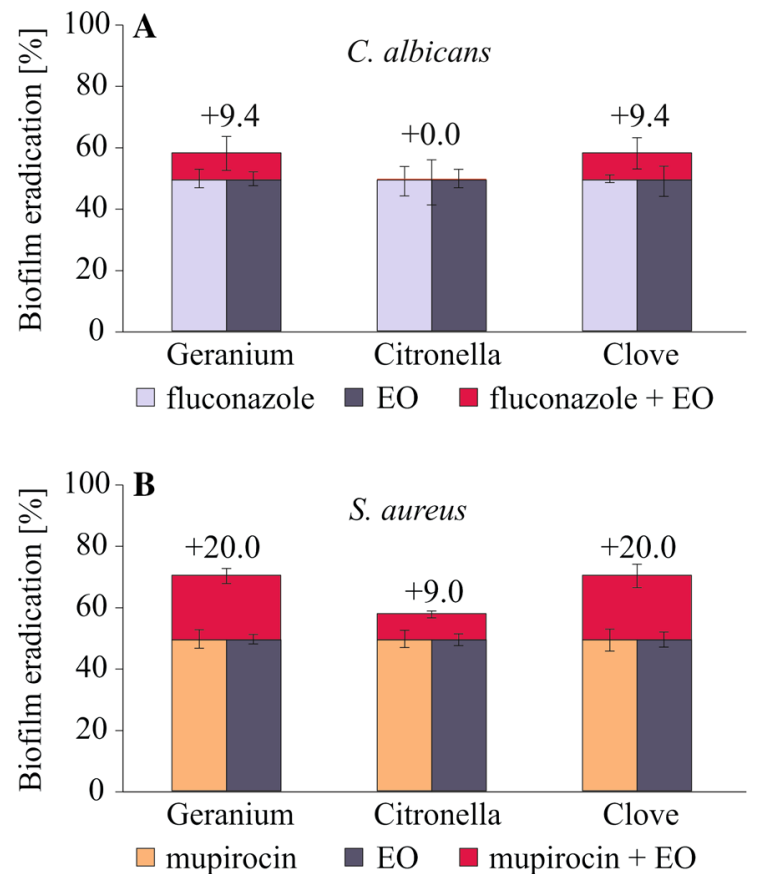

Fig. 1 A comparison of FLU, MUP and EOs activity used separately or in combination against C. albicans ATCC 10231 and $S$. aureus NCTC 8325-4 preformed mono-species biofilms, assessed by XTT reduction assay. The effect was evaluated by applying each agent at $\mathrm{MBEC}_{50}$ for $24 \mathrm{~h}$ of incubation: FLU (bright blue bars); MUP (orange bars); EO (navy blue bars); $\mathrm{FLU}+\mathrm{EO}$ or MUP + EO (upper red boxes; + the percentage of eradication enhancement). (Color figure online)

efficiency of mupirocin (Fig. 3-depicted as red boxes).

\section{Discussion}

The chemical characteristics of essential oils, performed by us previously, remain in compliance with the data published in this regard [13-15]. Noteworthy is the high content of eugenol in clove oil, citronellal and geraniol in citronella oil and citronellyl formate in geranium oil, which was absent in other EOs. Many authors [16-18] reported that eugenol and citral reduced bacterial adherence when used at sub-MIC, affected their virulence, and was not associated with any risk of resistance development. However, it remains to be determined which of the predominant citronella and geranium oil components could be responsible for their such strong activity, which in some contexts can be equal or higher than clove oil. It
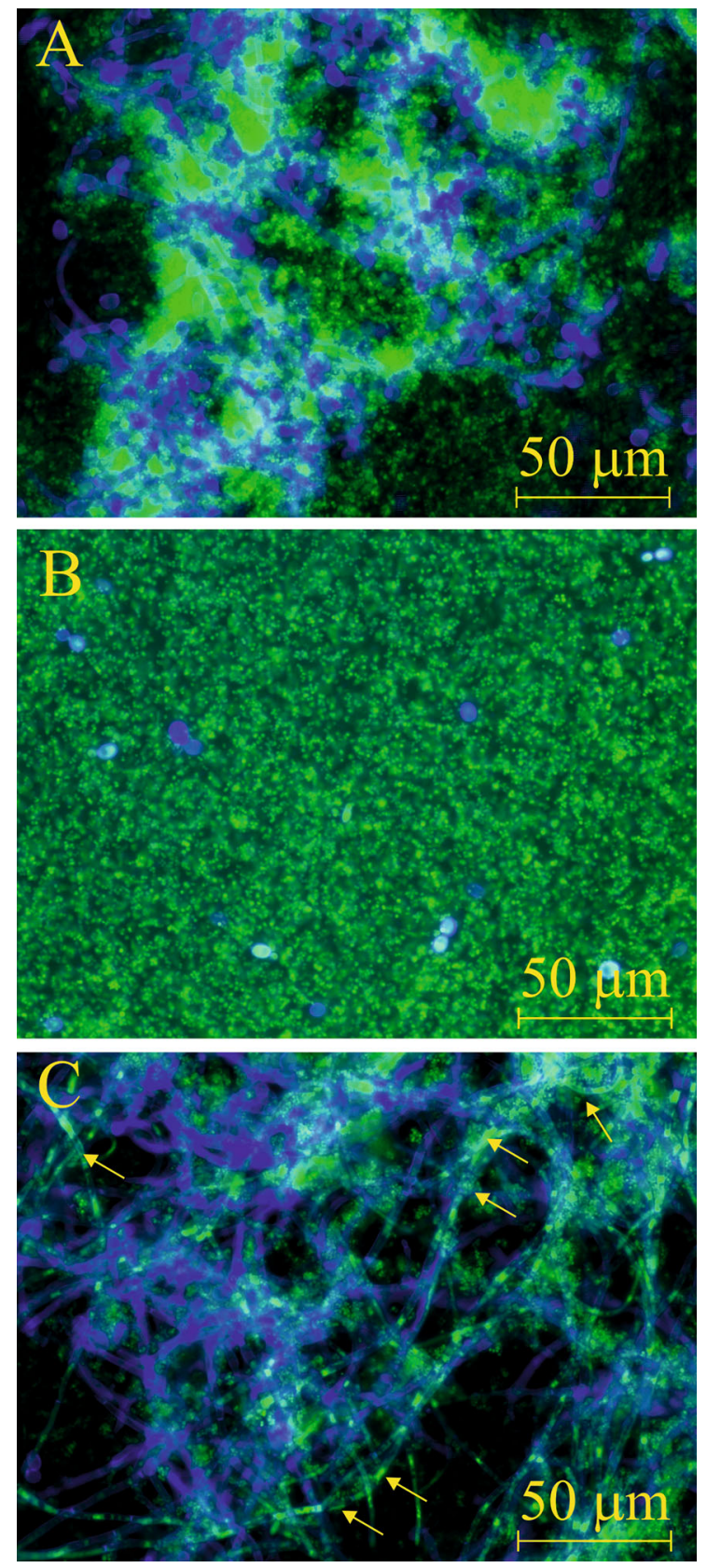

Fig. 2 Dual-species biofilms formed in three different variants of methodology: a yeast applied $2 \mathrm{~h}$ earlier than bacteria; b bacteria applied $2 \mathrm{~h}$ earlier than yeast; c yeast and bacteria applied simultaneously. Biomass developed in the chambers was stained with $5 \mu \mathrm{M}$ of SYTO $9+0.5 \mathrm{mg} / \mathrm{mL}$ of calcofluor white fluorescent dyes. S. aureus and C. albicans are stained green and blue, respectively. Large $S$. aureus aggregates adhered to $C$. albicans hyphae are indicated with arrows. The images were captured using AxioCam HRC camera combined with an Axiovert $200 \mathrm{M}$ (Zeiss, Germany) inverted microscope equipped with a Plan-Neofluar objective $(63 \times / 1.25$ Oil). (Color figure online) 


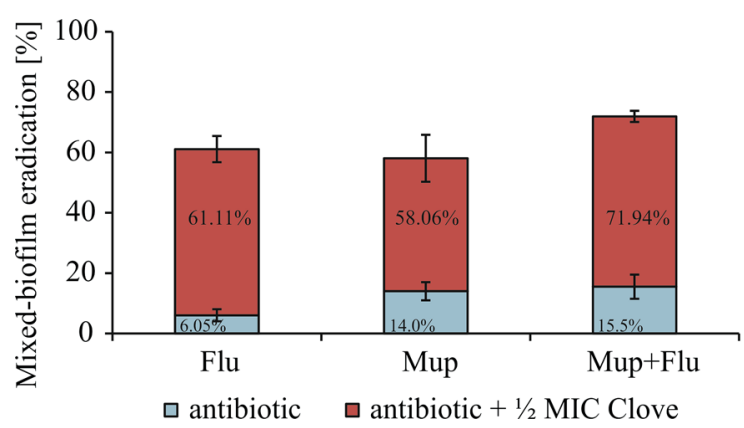

Fig. 3 A comparison of FLU, MUP, FLU + MUP (bottom blue bars) activity alone and combined with clove oil (upper red bars) against $C$. albicans ATCC 10231 and S. aureus NCTC 8325-4 preformed dual-species biofilms, evaluated by Alamar Blue reduction assay. The percentages of the biofilm eradication are typed in the appropriate bars. (Color figure online)

is important to note, however, that not always dominant constituent is responsible for the high antimicrobial potential of the essential oil in which rather synergistic activity of several components occurs.

Essential oils can be useful for medical purposes; nevertheless, they can affect both microbial and eukaryotic cells. The concentrations of EOs reported as antimicrobial are very often also cytotoxic [19-22]. Therefore, their use in topical therapy seems to be most reasonable, e.g., in the treatment of the wounds or ulcers complicated by polymicrobial infections. Interesting study in this respect has been presented by Kandimalla et al. [23] who reported anti-Candida and anti-inflammatory property of citronella oil in diabetic wound healing. Similar optimistic report published by Warnke et al. [24] concerns anti-bacterial activity of EOs mixture (mainly based on eucalyptus oil) in patients with incurable head and neck cancer and associated malodorous necrotic ulcers.

For many natural products, including essential oils, few mechanisms of anti-biofilm action are considered-the direct biocidal activity, inhibition of the expression of adhesins, interruption of intercellular communication and/or in the case of dimorphic fungi interference in morphogenesis [25-28]. Since both morphological forms play a role in C. albicans biofilm development, prevention of blastospores adhesion and their differentiation in filamentous form seems to be good therapeutic option. Such an effect of geranium, citronella and clove oil components has been previously described [17, 29] with clove oil as the most potent in this respect. Khan and Ahmad [30], similarly as in our study, reported an approximately $50 \%$ reduction in biofilm and germ tube formation of $C$. albicans by clove oil used at sub-MIC. Components of geranium and citronella oils have also been described as possessing antimicrobial activity, but precise mechanisms, other than the action on the integrity and function of the cytoplasmic membrane and various effects on microbial metabolome, remain not well known [19, 20, 30]. It is suggested that the enhanced effectiveness of conventional drugs by EOs may be attributed to so-called chemosensitization effect [8, 31-36]. However, these studies mostly concerned to mono-species biofilms or dual-species communities, but consisted of bacteria. Conversely, our report is one of the few to investigate the antibiofilm efficiency of EOs against dual-species fungalbacterial biofilms. A similar range of research has been published by Pekmezovic et al. [37] who demonstrated activity of pompia and grapefruit EOs against dual-species Pseudomonas aeruginosa and Aspergillus fumigatus biofilms. Harriott and Noverr [4] found that $C$. albicans $+S$. aureus biofilm exhibits an altered drug sensitivity profile compared to the monoculture: no difference in sensitivity of yeasts to amphotericin B but greatly enhanced resistance of staphylococci to vancomycin. A similar study, carried out by $\mathrm{Li}$ et al. [38], showed a synergistic effect of fluconazole and minocycline to combat C. albicans $+S$. aureus biofilm, but only against "young" mixed biofilm. In our study, the combination of FLU and MUP also did not cause much better eradication of dual-species biofilm, but the addition of EO gave a satisfactory effect. Thus, our in vitro model of dualspecies biofilm is a valid target for measuring of EOs activity. In conclusion, selected EOs could be used to develop the strategies to prevent/control fluconazoleresistant yeast or mupirocin- and methicillin-resistant staphylococci.

It is now widely accepted that bacterial/fungal coinfections result in increased colonization of host tissues and greater combined virulence and resistance [2, 6, 7, 33, 39]. Study by Kong et al. [40] using mouse model of oral candidiasis showed important clinical implications of this phenomenon. The authors demonstrated that yeast infection predisposes the host to development of disseminated bacterial ( $S$. aureus) disease. In further study, the same group of Kong et al. [41] found that when S. aureus and C. albicans grow together, enhanced bacteria tolerance to antimicrobial 
drugs occurs, mediated by fungal polysaccharides of the biofilm matrix. Similar observation has been recently published by Kean et al. [42] who showed in vitro and in vivo (Galleria mellonella model) that in polymicrobial biofilm other matrix component-extracellular DNA-supports $S$. aureus adhesion to yeast cells and promotes stability of the matrix. Larvae co-infection with both bacteria and fungi increased their mortality by approximately $20 \%$, and when miconazole was used as therapeutics, loss of drug efficacy was observed.

Acknowledgements The study was supported by the National Research Center, Poland, Grant No. 2011/01/N/NZ6/00317 and by University of Lodz for A.B. The authors wish to thank M. Więckowska-Szakiel for technical assistance.

\section{Compliance with Ethical Standards}

Conflict of interest The authors declare that they have no conflict of interest.

Open Access This article is distributed under the terms of the Creative Commons Attribution 4.0 International License (http:// creativecommons.org/licenses/by/4.0/), which permits unrestricted use, distribution, and reproduction in any medium, provided you give appropriate credit to the original author(s) and the source, provide a link to the Creative Commons license, and indicate if changes were made.

\section{References}

1. Sardi JC, Scorzoni L, Bernardi T, Fusco-Almeida AM, Mendes Giannini MJ. Candida species: current epidemiology, pathogenicity, biofilm formation, natural antifungal products and new therapeutic options. J Med Microbiol. 2013;62:10-24.

2. Harriott MM, Noverr MC. Candida albicans and Staphylococcus aureus form polymicrobial biofilms: effects on antimicrobial resistance. Antimicrob Agents Chemother. 2009;53:3914-22.

3. Harriott MM, Lilly EA, Rodriguez TE, Fidel PL, Noverr MC. Candida albicans forms biofilms on the vaginal mucosa. Microbiology. 2010;156:3635-44.

4. Harriott MM, Noverr MC. Ability of Candida albicans mutants to induce Staphylococcus aureus vancomycin resistance during polymicrobial biofilm formation. Antimicrob Agents Chemother. 2010;54:3746-55.

5. Kim HK, Thammavongsa V, Schneewind O, Missiakas D. Recurrent infections and immune evasion strategies of Staphylococcus aureus. Curr Opin Microbiol. 2012;15:92-9.

6. Klotz SA, Chasin BS, Powell B, Gaur NK, Lipke PN. Polymicrobial bloodstream infections involving Candida species: analysis of patients and review of the literature. Diagn Microbiol Infect Dis. 2007;59:401-6.
7. Peters BM, Jabra-Rizk MA, O’May GA, Costerton JW, Shirtliff ME. Polymicrobial interactions: impact on pathogenesis and human disease. Clin Microbiol Rev. 2012;25:193-213.

8. Campbell BC, Chan KL, Kim JH. Chemosensitization as a means to augment commercial antifungal agents. Front Microbiol. 2012;3:79.

9. Cui J, Ren B, Tong Y, Dai H, Zhang L. Synergistic combinations of antifungals and anti-virulence agents to fight against Candida albicans. Virulence. 2015;6:362-71.

10. Poovelikunnel T, Gethin G, Humphreys H. Mupirocin resistance: clinical implications and potential alternatives for the eradication of MRSA. J Antimicrob Chemother. 2015;70:2681-92.

11. Budzyńska A, Sadowska B, Lipowczan G, Maciąg A, Kalemba D, Różalska B. Activity of selected essential oils against Candida spp. strains. Evaluation of new aspects of their specific pharmacological properties, with special reference to Lemon Balm. Adv Microbiol. 2013;3:317-25.

12. European Committee on Antimicrobial Susceptibility Testing_EUCAST. http://www.eucast.org, 2012.

13. De Toledo LG, Ramos MA, Spósito L, Castilho EM, Pavan FR, Lopes Éde O, et al. Essential oil of Cymbopogon nardus (L.) Rendle: a Strategy to combat fungal infections caused by Candida species. Int J Mol Sci. 2016;17:E1252.

14. Ghannadi A, Bagherinejad M, Abedi D, Jalali M, Absalan B, Sadeghi N. Antibacterial activity and composition of essential oils from Pelargonium graveolens L'Her and Vitex agnus-castus L. Iran J Microbiol. 2012;4:171-6.

15. Wei LS, Wee W. Chemical composition and antimicrobial activity of Cymbopogon nardus citronella essential oil against systemic bacteria of aquatic animals. Iran J Microbiol. 2013;5:147-52.

16. Darvishi E, Omidi M, Bushehri AAS, Golshani A, Smith ML. The antifungal eugenol perturbs dual aromatic and branched-chain amino acid permeases in the cytoplasmic membrane of yeast. PLoS ONE. 2013;8:e76028.

17. Yadav MK, Chae S-W, Im GJ, Chung J-W, Song J-J. Eugenol: a phytocompound effective against methicillinresistant and methicillin-sensitive Staphylococcus aureus clinical strain biofilms. PLoS ONE. 2015;10:e0119564.

18. Apolónio J, Faleiro ML, Miguel MG, Neto L. No induction of antimicrobial resistance in Staphylococcus aureus and Listeria monocytogenes during continuous exposure to eugenol and citral. FEMS Microbiol Lett. 2014;354:92-101.

19. Sinha S, Jothiramajayam M, Ghosh M, Mukherjee A. Evaluation of toxicity of essential oils palmarosa, citronella, lemongrass and vetiver in human lymphocytes. Food Chem Toxicol. 2014;68:71-7.

20. Prashar A, Locke IC, Evans CS. Cytotoxicity of clove (Syzygium aromaticum) oil and its major components to human skin cells. Cell Prolif. 2006;39:241-8.

21. Russo R, Corasaniti MT, Bagetta G, Morrone LA. Exploitation of cytotoxicity of some essential oils for translation in cancer therapy. Evid Based Complement Altern Med. 2015;. doi:10.1155/2015/397821.

22. Sienkiewicz M, Głowacka A, Kowalczyk E, WiktorowskaOwczarek A, Jóźwiak-Bębenista M, Łysakowska M. The biological activities of cinnamon, geranium and lavender 
essential oils. Molecules. 2014;19:20929-40. doi:10.3390/ molecules 191220929.

23. Kandimalla R, Kalita S, Choudhury B, Dash S, Kalita K, Kotoky J. Chemical composition and anti-candidiasis mediated wound healing property of Cymbopogon nardus essential oil on chronic diabetic wounds. Front Pharmacol. 2016;7:198.

24. Warnke PH, Sherry E, Russo PA, Sprengel M, Açil Y, Bredee JP, et al. Antibacterial essential oils in malodorous cancer patients: clinical observations in 30 patients. Phytomedicine. 2006;13:463-7.

25. Jacobsen ID, Wilson D, Wächtler B, Brunke S, Naglik JR, Hube B. Candida albicans dimorphism as a therapeutic target. Expert Rev Anti Infect Ther. 2012;10:85-93.

26. Khan MS, Malik A, Ahmad I. Anti-candidal activity of essential oils alone and in combination with amphotericin B or fluconazole against multi-drug resistant isolates of Candida albicans. Med Mycol. 2012;50:33-42. doi:10.3109/ 13693786.2011.582890.

27. Peters BM, Ovchinnikova ES, Krom BP, Schlecht LM, Zhou H, Busscher HJ, et al. Staphylococcus aureus adherence to Candida albicans hyphae is mediated by the hyphal adhesin Als3p. Microbiology. 2012;158:2975-86.

28. Khan MS, Zahin M, Hasan S, Husain FM, Ahmad I. Inhibition of quorum sensing regulated bacterial functions by plant essential oils with special reference to clove oil. Lett Appl Microbiol. 2009;49:354-60.

29. Budzyńska A, Sadowska B, Więckowska-Szakiel M, Różalska B. Enzymatic profile, adhesive and invasive properties of Candida albicans under the influence of selected plant essential oils. Acta Biochim Pol. 2014;61:115-21.

30. Khan MS, Ahmad I. Biofilm inhibition by Cymbopogon citratus and Syzygium aromaticum essential oils in the strains of Candida albicans. J Ethnopharmacol. 2012;140:416-23.

31. Leite MCA, de Brito Bezerra AP, de Sousa JP, de Oliveira Lima E. Investigating the antifungal activity and mechanism(s) of geraniol against Candida albicans. Med Mycol. 2015;53:275-84.

32. Liu S, Hou Y, Chen X, Gao Y, Li H, Sun S. Combination of fluconazole with non-antifungal agents: a promising approach to cope with resistant Candida albicans infections and insight into new antifungal agent discovery. Int $\mathrm{J}$ Antimicrob Agents. 2014;43:395-402.
33. Zago CE, Silva S, Sanitá PV, Barbugli PA, Dias CM, Lordello VB, et al. Dynamics of biofilm formation and the interaction between Candida albicans and methicillin-susceptible (MSSA) and -resistant Staphylococcus aureus (MRSA). PLoS ONE. 2015;10:e0123206.

34. Krause J, Geginat G, Tammer I. Prostaglandin $E_{2}$ from Candida albicans stimulates the growth of Staphylococcus aureus in mixed biofilms. PLoS ONE. 2015;10:e0135404.

35. Fu Y, Zu Y, Chen L, Shi X, Wang Z, Sun S, Efferth T. Antimicrobial activity of clove and rosemary essential oils alone and in combination. Phytother Res. 2007;21:989-94.

36. Oliveira MMM, Brugnera DF, Cardoso MG, Alves E, Piccoli RH. Disinfectant action of Cymbopogon sp. essential oils in different phases of biofilm formation by Listeria monocytogenes on stainless steel surface. Food Control. 2010;21:549-53.

37. Pekmezovic M, Aleksic I, Barac A, Arsic-Arsenijevic V, Vasiljevic B, Nikodinovic-Runic J, et al. Prevention of polymicrobial biofilms composed of Pseudomonas aeruginosa and pathogenic fungi by essential oils from selected Citrus species. Pathog Dis. 2016;. doi:10.1093/femspd/ ftw102.

38. Li H, Zhang C, Liu P, Liu W, Gao Y, Sun S. In vitro interactions between fluconazole and minocycline against mixed cultures of Candida albicans and Staphylococcus aureus. J Microbiol Immunol Infect. 2015;48:655-64.

39. Schlecht LM, Peters BM, Krom BP, Freiberg JA, Hänsch GM, Filler SG, et al. Systemic Staphylococcus aureus infection mediated by Candida albicans hyphal invasion of mucosal tissue. Microbiology. 2015;161:168-81.

40. Kong EF, Tsui C, Kucharíková S, Andes D, Van Dijck P, Jabra-Rizk MA. Commensal protection of Staphylococcus aureus against antimicrobials by Candida albicans biofilm matrix. MBio. 2016;7:e01365-16. doi:10.1128/mBio. 01365-16.

41. Kong EF, Kucharíková S, Van Dijck P, Peters BM, Shirtliff ME, Jabra-Rizk MA. Clinical implications of oral candidiasis: host tissue damage and disseminated bacterial disease. Infect Immun. 2015;83:604-13. doi:10.1128/IAI.02843-14.

42. Kean R, Rajendran R, Haggarty J, Townsend EM, Short B, Burgess KE, Lang S, et al. Candida albicans mycofilms support Staphylococcus aureus colonization and enhances miconazole resistance in dual-species interactions. Front Microbiol. 2017;8:258. doi:10.3389/fmicb.2017.00258. 